\title{
Problems, Expectations, and Recommendation in Guidelines for Implementation of COVID-19 Prevention Health Protocols in the Workplace in Bali Province; a Qualitative Study
}

\author{
Ariyani Wayan $^{1 *}$ (D), I. Putu Suiraoka ${ }^{1,2}$, A. A. N. Kusumajaya ${ }^{1}$, I. Nyoman Gejir ${ }^{1}$, I. G. A. Darmawati ${ }^{1}$, I. Made Sukarja ${ }^{1}$, I. Wayan \\ Juniarsana $^{1,2}$, Ni Nengah Ariati ${ }^{1}$, I. G. P. Sudita Puryana ${ }^{1}$, D. A. A. Posmaningsih ${ }^{1,2}$, I. Wayan Jana ${ }^{1}$, I. B. Oka Suyasa \\ ${ }^{1}$ Department of Health, Health Polytechnic, Ministry of Health Denpasar, Denpasar, Indonesia; ${ }^{2}$ Center of Excellence in Science \\ and Technology, Health Polytechnic, Ministry of Health Denpasar, Denpasar, Indonesia
}

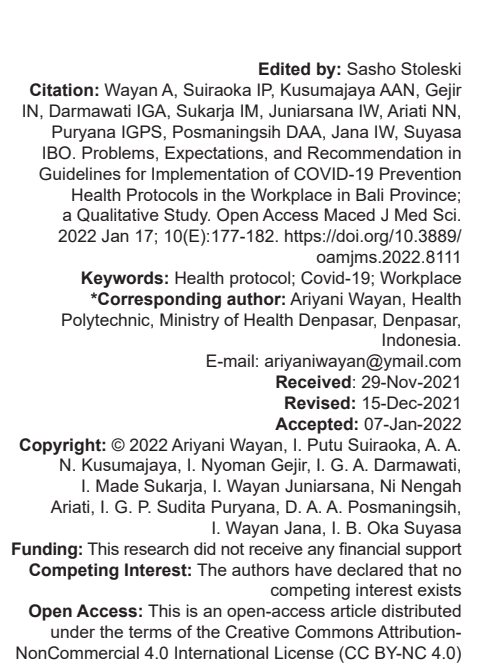

\section{Abstract}

BACKGROUND: Formal and informal sector worker is encouraged as the agent of change in the new normal era They are demanded to perform adequate health measures, stay productive, and prevent the spread of COVID-19. Health protocol guidance has been issued and introduced to guide the initiative of COVID-19 prevention and control.

AIM: This study aimed to describe the issues encountered during the implementation of the health protocol, the expectation, and recommendations for the current health protocol guidance in the workplaces setting.

METHODS: This qualitative study enrolled a descriptive-exploratory design. We explored that the issues and hindrances had encountered during the execution of the guidance, the expectation, and recommendation. Eligible study participants recruited by the purposive sampling technique. Data were collected on June 2021 by directing sessions of focus group discussion. The collected data then analyzed by the thematic approach employing QSR Nvivo 12.

RESULTS: Several issues identified were the vagueness of the parties responsible for the oversight and enforcement function on several issues or fields, lack of intensive dissemination of the importance of health measures in preventing COVID-19 transmission by the authorized officers, and inadequate health measures implementation. Participants yearned for more comprehensive and clear technical guidance. Health promotion education also suggested being included in the guidance.

CONCLUSION: This study proposed the establishment of a more comprehensive, clear, and brief guidance to induce its adequate execution of health measures or protocols.

\section{Introduction}

The nature of the national health development plan is attempts carried out to enable control over their awareness, will, and ability to live a healthy life, pursuing the highest degrees of public health. At present, the entire world is shaken by the devastating pandemic, coronavirus disease 2019 (COVID-19). The uncontrolled number of COVID-19 confirmed cases indicated the need for clear and upfront planning to manage the situation [1].

Vaccination yields new hope to countermeasure the COVID-19 pandemic. However, getting vaccinated is not equal to being immune to COVID-19 infection. However, it protects people from a severe degree of COVID-19 infection. No studies have found the exact duration of immunity produced by the vaccine administration. It could last for 6 months, 1 year, 2 years, and so on. Therefore, before gaining herd immunity, adequate health protocol implementation is obliged for the community members. High confirmed cases of COVID-19 in several countries generated by inadequate health measures, the emergence of a more contagious virus strain, and low vaccination coverage [2].

These days, Indonesia is facing a massive challenge that requires sudden adjustment to the COVID-19 pandemic situation. Unavailable definitive therapies and a limited number of vaccinations, as if prophesied a long period of pandemic and the need to consider a new way of life. Community protection from the pandemic, including free vaccination programs, should have been prioritized. Harmful threats posed by the pandemic required a high amount of funds to ensure the community's safety and economic security, especially after lockdown policies enforcement. However, the alternatives are limited. National and local government needs to take the solid initiative to eradicate confirmed cases, or 
at least sloped the curve. Sufficient funds should have provided to curb the transmission and ensure community wellness. Other non-COVID-19 fund sources would be effective if re-allocated to manage the COVID-19 situation [2].

Health, social, and economic plans need to be complemented each other to make a good combination of strategies in achieving the desired goals [3]. COVID-19 control policies should be in line with the economic and social recovery program. Public space is an area that is generally open to social gatherings and accessible to people to meet their daily needs. The impact of the pandemic on the global economic state is massive and devastating [4]. Pandemic has threatened local and national economic stability. Moreover, it delivered a worse outcome on the area that had faced economic instability even far before the pandemic. To avoid further decline in national stability, rapid initiatives have been taken by the government to curb the transmission of the virus [5].

COVID-19 has been presented a shocking impact on Bali's economic state. Furthermore, Bali has high COVID-19 confirmed cases due to rapidly increased clusters in the community. The risk of crowd movement and social interactions or gatherings in workplaces had contributed to the COVID-19 transmission. On the other hand, three central areas in Bali have been designated as the green zone area by the Minister of Health and the Minister of Tourism and Creative Economy. Those areas are Ubud (Gianyar Regency), ITDC Nusa Dua (Badung Regency), and Sanur (Denpasar City). The establishment of the areas aimed to provide free COVID-19 spaces for the free COVID corridor (FCC) program. FCC is a program arranged to deliver a new pattern of tourism tours that are free of COVID-19. People who are living in the area must be fully vaccinated.

COVID-19 mitigation strategies in workplaces require to recover from the economic crisis and simultaneously prevent the risk of getting infected. Apart from the tourism sector, Bali has formal and informal sectors that also need to be actively involved in preventing COVID-19 transmission. Worker has been encouraged as an agent of change, demonstrating adequate implementation of health protocols in the community. It intended to persuade the community to adopt new-normal life and health protocols adequately, continuing a productive life with a lower risk of getting infected by COVID-19. Health protocols guidance required to guide the implementation of the measures in the workplace setting. However, issues might be encountered during the implementation of the guidance. Community expectations and recommendations about the guidance might help the stakeholder to solve the issues. Hence, this study aimed to describe the issues, expectations, and recommendations of the current health protocol guidance in the workplace setting.

\section{Study Methods}

\section{Design}

This was a descriptive-exploratory and qualitative study [6]. In the setting of formal and informal sectors, we explored the implementation of the guidance of health protocols, together with its issues, barriers, recommendations of practices, and expectation. In addition, workers' compliance with the health measures set during the pandemic was also examined.

\section{Study location and duration}

This study was conducted in one city (Denpasar) and two regencies (Badung and Gianyar) in Bali Province. The study location was picked due to the designation of these areas as the green zone in Bali Province. COVID19 Task Force, representatives from the Local Board of Health, and representatives from the Local Board of Manpower were enrolled as study participants.

\section{Participant recruitment}

A purposive sampling technique was employed to select eligible study participants. Participants' criteria were picked carefully according to the study requirements. Informed consent was administrated before the data collection. Interview sessions with the representative from the Civil Service Police Unit, Assembly of Village Representative, Local Board of Health, and Local Board of Manpower in each City and Regency were conducted to gather the data of health protocol guidance implementation, its issues, barriers, and the compliance in the formal and informal setting. Each board was composed of the governmental-based institution or village element that portrayed each unit charged with the responsibility to monitor, supervise, and disseminate the importance of health measures in preventing the spread of COVID-19.

\section{Data collection}

This study was conducted on June 2021 in Denpasar Health Polytechnic. Eligible participants classified into two groups and asked to engage in a focus group discussion (FGD). FGD preparation included guidelines, recorders, and facilitators organized before the session. A leader from the research team and a list of questions escorted the FGD sessions. Several questions were probed to collect adequate data for the analysis. All sessions of FGD were recorded by the research team.

\section{Data analysis}

The thematic approach by QSR Nvivo 12 applied to analyze the qualitative data set [7]. Recorded 
data were organized in a verbatim transcription, while the study scheme arranged based on questions listed in the FGD guidelines. After the transcription was being read thoroughly, the codes were translated into topics and sub-topics [8]. Field observation as the data triangulation method had employed to validate data collected in the FGD sessions [9].

\section{Ethics}

Before conducting research, ethical clearance had been obtained from Institutional Ethical Committee Review Board Denpasar Health Polytechnic, Ministry of Health of the Republic of Indonesia.

\section{Results}

In this study, we recruited 14 participants that distributed into two groups. Each group consisted of seven participants who portrayed each element of a governmental-based institution or village assembly: Local Board of Manpower, Civil Service Police Unit, and Assembly of Village Representative. Each unit represented parties charged with the responsibility to monitor, supervise, and disseminate the importance of health measures in preventing the spread of COVID-19.

There were two themes identified in the FGD sessions: (1) Health protocol guidance and (2) health behavior in preventing COVID-19 transmission. The theme of health protocol guidance dissolved into two subtopics: (1) Expectation and recommendation of the health protocol guidance and (2) issue encountered during the implementation of health protocol technical. The health behavior theme also grouped into two sub-topics: Community and workers' understanding about COVID19 and (2) health measures compliance among the community and workers in formal and informal sectors.

The study framework is shown in Figure 1.

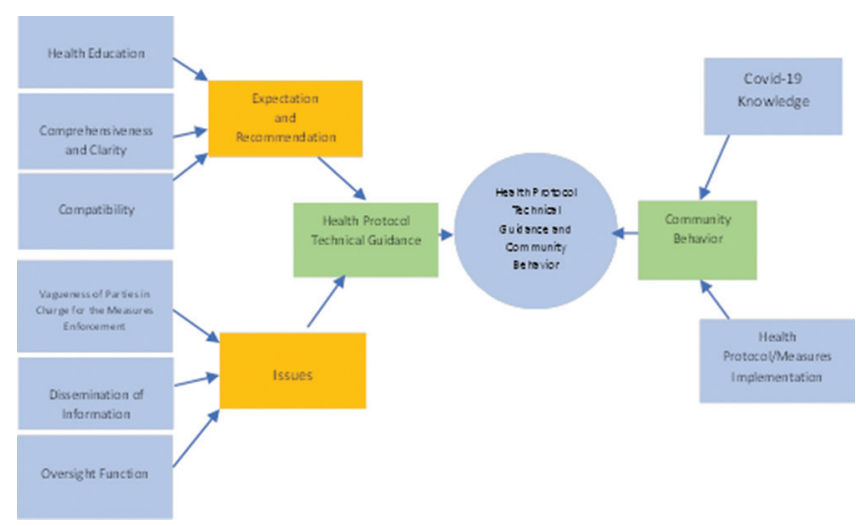

Figure 1: Concept Map Of The Problems, Expectations, and Recommendation in Guidelines for Implementation of COVID-19 Prevention Health Protocols

\section{Theme 1 health protocol guidance in} preventing COVID-19 transmission

This theme classified into two sub-topics: Expectation and recommendation of the health protocol guidance and issue encountered during the implementation of health protocol technical.

Sub-theme 1.1 expectation and recommendation of the health protocol technical guidance

The sub-topic of expectation and recommendation of the health protocol guidance dissolved into three parts of more specific topics. Those topics are elaborated as follow:

Recommendation to intensify the portion of health education

Participants wished for more information about a healthy lifestyle on the health protocol technical guidance. A health guide of ideal nutrition intake, physical activity, rest, and other forms of healthy lifestyles to improve the immunity system during the pandemic would be essential for the community.

\begin{abstract}
"Adding more portion of health education would be good" $R 10$

"The ideal nutritional intake that required to maintain healthy body and enhance the immune system need to be included in the guidance to prevent and eradicate COVID infection, or maybe the behavior needed to enhance immunity" $R 12$
\end{abstract}

Expectation and recommendation of a comprehensive and clear health protocol guidance

The participant desired an uncomplicated and comprehensive health protocol technical guidance. They claimed that the recent guidance did not provide clear technical instructions and guides. Participants struggled to enforce the measures because of the lack of clarity in the health protocol technical guidance.

"Did they understand about the instructed components on the guidance? For instance, the instruction of the temperature screening, did they know the range of normal body temperature? And the objective of the screening? Have they exposed to the information? Set clear standard for the instructed component" $R 6$

"The instruction to enroll $25 \%$ or $50 \%$ of WFH was not clear, how come they set this standard? The area of the workplace and number of staff should have considered to implement this policy" $R 1$ 
"For the religious activity...., the standard needs to be clearer, how many people constitute a crowd in this activity?" $R 1$

"For example, the acceptable range of temperature to work...the standard should have clearly elaborated in this guidance. Beside that..." R 6

Expectation and recommendation of the compatibility of the health protocol guidance of COVID-19 prevention with the other policies or guidance issued

Policies were issued by governmental or non-governmental-based institutions during the pandemic [10], [11], [12]. The guidance should be lined with these policies. This compatibility is essential to prevent confusion in executing the health measures. Below is elaborated several excerpts from the FGD sessions:

"The guidance should have organized according to the regional policies; hence, it did not clash the local policies" $R 6$

"The guideline should have lined with the regional regulation....It need to be developed as simple practical guidelines" $R 6$

"There are too many policies issued, we have tried to execute it well, we hope those policies are in line with each other" $R 2$

Sub theme 1.2 issues on the supervision and enforcement of the health measures

The second sub-theme dissolved into three sub-topics: The vagueness of the parties who run the oversight and enforcement function on the certain issues or fields, oversight function improvement, and the need of intensive dissemination of the importance of health measures in preventing COVID-19 transmission by the authorized officers.

The vagueness of the parties who run the oversight and enforcement function on the certain issues or fields

Authorized officers who run the oversight and enforcement function are composed of varied elements of the community. However, the involvement of the authorized officers was absent in several issues that happened during the enforcement of the health measures. Below is the participant's argument about the situation:

"Foreigners contributed to the high number of positive cases here. Then, self-quarantine was suggested for them, ... but the question is: Who will be responsible for controlling and ensuring this quarantine enforcement?" $R 5$
"The indigenous village-based market in Bali is controlled by local community self-help-basedCOVID-19 Task Force. However, their control was quite weak on the non-indigenous-villagebased market" $R 5$

"For instance: Indomart has violated the health measures during the pandemic, then who will be in charge of addressing the violation?" $R 5$

"People who are responsible of the enforcement of the health measure in the workplaces" $R 14$

The need of intensive dissemination of the importance of health measures in preventing COVID-19 transmission by the authorized officers

According to the data collected from the FGD sessions, the community seemed reluctant to perform proper health protocol after the vaccination. This situation indicated the need for intensive dissemination of the importance of health measures in preventing COVID-19 transmission by authorized officers.

"No explanation of the duration of immune protection after the vaccination provided" $R 4$

"Why did they think that vaccination equal to immune from COVID infection? Because the lack of information given about the vaccine, they tried to find information about vaccine by themselves, which was mostly from social media platforms... but could not differentiate the right and misleading information" $R 7$

"Intensive information dissemination is essential, mainly during the emersion of the new variant of COVID-19" $R 7$

"Consistent information dissemination about proper health measures implementation should have delivered by the authorized officers to minimize confusion among the community member" $R 6$

The need of oversight function improvement on the health protocols implementation in preventing COVID-19 transmission

Data also showed that the oversight function required to be improved. The oversight function from the authorized parties was absent in several fields. It revealed by these excerpts:

"Weak monitoring of the implementation of the measures, especially among the community members" $R 13$

"Oversight function needs to be stressed and consistently conducted by the authorized parties" $R 13$

"We should conduct more strict monitoring in the future." $R 3$ 


\section{Topic 2 health behavior of the community}

This topic separated into two sub-topics. The first sub-topic was the lack of knowledge of the vaccination goals and the COVID-19 method of transmission. The second sub-topic was the health measures implementation among workers and community members in formal and informal sectors.

Sub-topic 2.1 the lack of knowledge of the vaccination goals and the COVID-19 method of transmission

The behavioral change occurred among the community members after the vaccination programs. The implementation of the health measures appeared to be softened, especially in informal sectors. Misunderstanding of the goal of COVID-19 vaccination and COVID-19 method of transmission may lead to behavioral change.

"Because of the plan to initiate the re-opening of tourism activity, and being fully vaccinated.... all of this things had added up to conclusion that they are free of COVID" $R 6$

"People tended to assume that after the vaccination; they would be free of COVID" $R 5$

\section{Sub-topic 2.2 health protocol implementation}

In line with the previous explanation, compliance with the health protocol was slightly declined in informal sectors. It might be attributed to the lack of knowledge among the community. Contrary, the health measures were well implemented informal sectors. However, the compliance was weakened during the break period. Here are several quotations from the FGD sessions:

"If we talk about the formal and informal setting, I remembered that we just run an event involving 1040 participants. We shared about the proper implementation of health measures in workplaces there. That hotel and restaurant had applied very strict health protocols"

"In the formal sector, the critical points were during the period of working, meeting, and taking the attendance. During the break, recovering from exhaustion, praying, or on the business trip. Bigger formal sectors were more structured (by meeting specific requirements)" R 14

"Canteen is known as an area that completely ignored the enforcement of the health protocols" $R 14$

"We noted 2793 health protocol violators per today; we had identified increasing number of measures violation from January to June $2021 " R 4$

\section{Discussion}

Policies issued have to address the existing health issues in the community. Self-awareness, adequate therapy, source of disease elimination, and health education are necessary to eradicate the cause of epidemic or pandemic in Indonesia [1].

Health protocols of the COVID-19 countermeasures classify into the stage of prevention, detection, and response [13]. Active participation from all layers of the community is highly required to curb the transmission. COVID-19 preparedness guidelines have been issued to control the virus transmission. Everyone has a role to play. Each community member obliges to do these health measures in the prevention stage: Wearing the well-fitted mask, wearing gloves, using hand sanitizer/ disinfectant, hand washing with soap, no face-touching, no handshaking, avoiding gathering or waiting in long-line, no object/surface-touching in the public areas, avoid taking public transportation, keeping a safe distance at least $2 \mathrm{~m}$ from other people, keep the immune system healthy, and immediately report any symptoms of illness [14], [15].

Supervision to the community health and public health measures compliance should place as a standard. It becomes a crucial point during the pandemic. Another administrative initiative that needs to be addressed is health supervision among the high-risk worker population in all workplaces. Supervision would bring essential impact and prevent the undesirable effect of the works. Workers with fever or other infectious disease symptoms could be detected and treated early, hence would produce a better outcome. Policies also need to be arranged to ensure all exposed workers could get convenient access to report any kind of symptom to their supervisor and health professionals [11]. Several other similar regulations have also been issued by the International Labor Organization and the WHO [16], [17].

Community protection from pandemic threats, including free vaccination programs, should have prioritized [2]. Even though the rapid-response of vaccination has initiated by the national government, the rate of transmission and new variant mutation of the virus are still challenging. Through the vaccination program, the country is on a path to so-called herd immunity. This program unlocks the possibility of a productive community, socially, and economically [2].

Astudy conducted by Mardhia et al. (2020) among the fishers revealed that $93 \%$ and $7 \%$ of participants had a good and excellent level of COVID-19 knowledge, respectively. However, knowledge could not present essential roles of COVID-19 prevention and control without adequate compliance to the health measures. Data from the FGD sessions confirmed the poor level of health measures adherence among the community [18]

The high rate of non-compliance with COVID-19 public health measures should not have 
occurred. We need to realize that the world is nowhere near the COVID-19 pandemic. New-normal life requires to be adopted. The high number of COVID-19 confirmed cases worldwide commonly driven by low compliance rates to public health measures, initiating the emergence of the new variant of the virus [2], [19]. New normal life refers to a state of getting back to normal activity before the pandemic, but it is ruled under strict public health measures such as physical distancing, wearing a well-fitted mask, social distancing, and frequent hand washing [1].

\section{Conclusion and Recommendation}

We recognized several issues during the implementation of the technical guidance: (1) The vagueness of the parties who responsible for the oversight and enforcement function on certain issues or fields, (2) the need for oversight function improvement, (3) the need for intensive dissemination of the importance of health measures in preventing COVID-19 transmission by the authorized officers, and (4) weak health measures implementation in informal sectors and weak point of implementation during the break period in formal sector. Participants agreed that the guidance required to (1) include or intensify the portion of health education and (2) provide a comprehensive and clear technical guidance. Participants declared that they were struggled to enforce the measures because of the lack of clarity in the current health protocol technical guidance. We suggest organizing a comprehensive, clear, and brief guidance to induce its adequate execution of health measures or protocols.

\section{Acknowledgment}

We would like to extend our gratitude to: (1) Directorate of Occupational and Sports Health, Ministry of Health, (2) Health Polytechnic of Ministry of Health Denpasar, and 3) Ganesha Widyaiswara Foundation. We also thank all participants for the precious supports and contribution in this study.

\section{References}

1. Wahidah I, Andi M, Rafqie M, Salsabila Hartono N, Attalah R. The COVID-19 pandemic: Analysis of government planning in prevention efforts. J Manajemen Organ. 2020;11:173-88. https://doi.org/10.29244/jmo.v11i3.31695

2. Muhamad SV. Pandemi COVID 19 Sebagai Persoalan Serius Banyak Negara Di Dunia Bidang Hubungan Internasional Kajian Singkat Terhadap Isu Aktual dan Strategis, Jakarta; 2020.

3. Mustafa SK, Ahmad MA, Baranova V, Deineko Z, Lyashenko V, Oyouni AA. Using wavelet analysis to assess the impact of COVID-19 on changes in the price of basic energy resources. Int J Emerg Trends Eng Res. 2020;8:2907-12. https://doi. org/10.30534/ijeter/2020/04872020

4. Kaushik MGN. The impact of pandemic COVID-19 in workplace. Eur J Bus Manage. 2020;12(15):1-10.

5. Erni PK. Dampak Pandemi COVID 19 Terhadap Penurunan Kesejahteraan Kota Pontianak. Seminar Akademik Tahunan IImu Ekonomi dan Studi Pembangunan, Pontianak; 2020.

6. Ritchie J, Lewis J, Nicholls CM, Ormston R. Qualitative Research Practice: A Guide for Social Science Students and Researchers. London: Sage; 2003.

7. Vaismoradi M, Turunen HB. Content analysis and thematic analysis: Implications for conducting a qualitative descriptive study. Nurs Health Sci. 2013;15:398-405.

8. Edhlund B, McDougall A. NVivo 12 Essentials; Your Guide to Leading Qualitative Data Analysis Software. Sweden: QSR International Ltd.; 2019.

9. Tong A, Sainsbury PC. Consolidated criteria for reporting qualitative research (COREQ): A 32-item checklist for interviews and focus groups. Int $\mathrm{J}$ Qual Health Care. 2007;15(6):349-57.

10. Governor of Bali. Regulation of the Governor of Bali Number 10 of 2021 Concerning Implementation of Discipline and Enforcement of Health Protocols as an Effort to Prevent and Control Corona Virus Disease 2019 in the New Era of Living Order; 2021.

11. WHO, ILO. Keselamatan dan Kesehatan Kerja Dalam keadaan Darurat Kesehatan Masyarakat. Jenewa: WHO; 2018.

12. Ministry of Health I. Pedoman Pencegahan dan Penanggulangan COVID-19 di Tempat Kerja. Jakarta: Indonesian Ministry of Health, ILO; 2020.

13. Suni NS. Kesiapsiagaan Indonesia Menghadapi Potensi Penyebaran Corona, Jakarta; 2020

14. Ministry of Health. Pedoman Kesiapsiagaan Menghadapi Corona Disease (COVID-19). $3^{\text {rd }}$ ed. Jakarta: Ministry of Health; 2020.

15. Khalid MS, Aljohani MM, Alomrani NA, Oyoun AA, Alzahrani $O$, Ahmad MA, et al. COVID-19 and immune function-"a significant" zinc. Oriental J Chem. 2020;36(6):1026-36. https://doi. org/10.13005/ojc/360604

16. ILO, IFC. Better Work Indonesia; Compilation of Guidelines on COVID-19 Transmission, Prevention and Management and the Best Practices in the Workplace. Jakarta: IFC; 2020.

17. WHO. Getting Your Workplace Ready for COVID-19. Geneva: WHO; 2020

18. Mardhia D, Kautsari N, Syaputra LI, Ramdhani W, Rasiardhi CO. Implementation of the Health Protocol and the Impact of Covid 19 on the Prices of the Fishery Community and Fishing Activities. Indones J Appl Sci Technol. 2020;1(2):80-7.

19. Telles CR, Roy A, Ajmal MR, Mustafa SK, Ahmad MA, de la Serna JM, et al. The impact of COVID-19 management policies tailored to airborne SARS-CoV-2 transmission: Policy analysis. JMIR Public Health Surveill. 2021;7(4):e20699. https://doi. org/10.2196/20699 